\title{
EFFICIENT AND CONVENIENT SYNTHESIS OF SYMMETRICAL CARBOXYLIC ANHYDRIDES FROM CARBOXYLIC ACIDS WITH SULFATED ZIRCONIA BY PHASE TRANSFER CATALYSIS
}

\author{
$\mathrm{Yu}$ Lin $\mathrm{Hu}^{1}$, Xing E Zhao ${ }^{2}$ and Ming $\mathrm{Lu}^{1 *}$ \\ ${ }^{1}$ Chemical Engineering College, Nanjing University of Science and Technology, Nanjing \\ 210094, PR China \\ ${ }^{2}$ Nanjing Simcere Pharmaceutical Co., Ltd, Nanjing 210042, PR China
}

(Received July 29, 2010; revised November 1, 2010)

\begin{abstract}
An efficient and convenient procedure for the synthesis of symmetrical carboxylic anhydrides from carboxylic acids with sulfated zirconia by PEG-1000 phase transfer catalysis has been developed. The reactions proceeded under mild and solvent-free conditions to provide the carboxylic anhydrides in good to excellent yields. The product can be isolated by a simple extraction with organic solvent, and the catalyst system can be recycled or reused without any significant loss of catalytic activity.
\end{abstract}

KEY WORDS: Carboxylic anhydrides, Carboxylic acids, $\mathrm{SO}_{4}{ }^{2-} / \mathrm{ZrO}_{2}$, Phase transfer catalysis

\section{INTRODUCTION}

Carboxylic anhydrides are important classes of chemicals that have been used extensively as synthetic intermediates in the preparation of a variety of fine or special chemicals such as amides, esters, peptides, drugs, etc [1-3], and many publications in the open literature have been found in synthesis of these type of compounds [3]. Generally speaking, they are prepared by dehydration of carboxylic acids with powerful acylating or dehydrating agents such as acid chlorides [4], acid anhydrides [5], thionyl chlorides [6, 7], sulfonyl chlorides [8], phophoranes [9], phosgene [10], pyridazin-3(2H)-ones [11, 12], ketene [13], imidazolinium chlorides [14], 1,3,5-triazines [15], DCC [16], dinitrogen tetroxide [17], chlorosulfonyl isocyanate [18], carbodiimides [19], trichloroacetonitrile/triphenylphosphine [20], and $\mathrm{P}_{2} \mathrm{O}_{5}$ [21]. Carboxylic anhydrides can also be prepared by the reaction of acid chlorides with carboxylates [22, 23] or carboxylic acids [24-27], as well as by reaction of acid chlorides under ultrasound basic media [28]. However, some of these procedures are invariably associated with one or more disadvantages such as long reaction time, high temperature, low yields and harmful to the environment. Consequently, there is a great need to develop new and environment-benign procedures that address these drawbacks for the synthesis of anhydrides.

Phase transfer catalysis (PTC) is a versatile synthetic technique that has been widely applied to intensify otherwise slow heterogeneous reactions involving an organic substrate and an ionic reactant, either dissolved in water (liquid-liquid) or present in solid state (liquid-solid) [29, 30]. In addition, phase transfer catalysis can make reaction condition gentle, can effectively avoid side reaction to occur, can reduce consumption of organic solvent and raw materials and enhance the efficiency of organic synthesis. At present, phase transfer catalysis has been applied in various organic syntheses, such as electrophilic substitution reaction, nucleophilic substitution reaction, hydrolysis and so on [31-34]. Recently, the use of zirconia based solid acids has been received considerable attention in different areas of organic synthesis, because of their environmental compatibility, reusability, greater selectivity, operational simplicity, nontoxicity, noncorrosiveness, low cost and ease of isolation [35]. Among the promoted $\mathrm{ZrO}_{2}$ solid acid catalysts, the sulfated zirconia $\left(\mathrm{SO}_{4}{ }^{2-} / \mathrm{ZrO}_{2}\right)$ become more popular because of its

*Corresponding author. E-mail: luming1963@163.com 
strong acidity and high activity in light alkane conversions at relatively mild temperatures [36, 37]. In this paper, we wish to report an efficient and convenient method for the preparation of symmetrical carboxylic anhydrides from the corresponding carboxylic acids with sulfated zirconia by phase transfer catalysis without any organic solvents (Scheme 1).

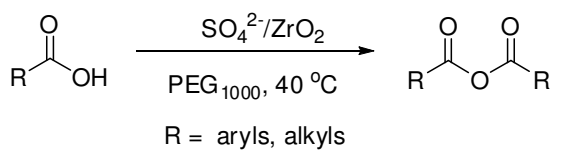

Scheme 1. Synthesis of symmetrical carboxylic anhydrides.

\section{EXPERIMENTAL}

\section{Apparatus and reagents}

All the chemicals used were from commercial sources without any pretreatment. All the reagents were of analytical grade. ${ }^{1} \mathrm{H}$ NMR spectra were recorded on a Bruker $400-\mathrm{MHz}$ spectrometer using $\mathrm{CDCl}_{3}$ as the solvent with tetramethylsilane (TMS) as an internal standard. Elemental analyses were performed on a Vario EL III instrument (Elmentar Anlalysensy Teme $\mathrm{GmbH}$, Germany). High performance liquid chromatography (HPLC) experiments were performed on a liquid chromatograph (Dionex Softron GmbH, USA), consisting of a pump (P680) and ultraviolet-visible light detector (UVD) system (170U). The experiments were performed on Diacovery C18 column, $\varnothing 4.6 \times 250 \mathrm{~mm}$. IR spectra were recorded on a Perkin Elmer PE-983 infrared spectrometer as $\mathrm{KBr}$ pellets with absorption in $\mathrm{cm}^{-1}$.

\section{Preparation of sulfated zirconia}

The sulfated zirconia catalyst was prepared by equilibrium adsorption of sulfate species on the surface of hydrous zirconium oxide samples. The hydrous zirconia catalysts were prepared by precipitation method using $\mathrm{ZrOCl}_{2} 8 \mathrm{H}_{2} \mathrm{O}$ and liquid ammonia solutions. Required amount of zirconyl chloride solution was added dropwise to deionised water. The $\mathrm{pH}$ was maintained at 10.0 by controlled addition of ammonia solution to the reaction mixture. The precipitated solution was stirred for $16 \mathrm{~h}$ at $35{ }^{\circ} \mathrm{C}$ followed by filtration and washing with double distilled water until free from chlorine ions. The hydroxide precipitate were subsequently dried overnight at $100{ }^{\circ} \mathrm{C}$ and calcined at $250{ }^{\circ} \mathrm{C}$ for $24 \mathrm{~h}$. To prepare sulfated $\mathrm{ZrO}_{2}$ catalyst, a portion of the obtained hydrous zirconia sample was ground to fine powder and immersed in $1 \mathrm{M} \mathrm{H}_{2} \mathrm{SO}_{4}$ solution. Excess water was evaporated on a water-bath and the resulting sample was oven-dried at $120{ }^{\circ} \mathrm{C}$ for $12 \mathrm{~h}$ and calcined at $500{ }^{\circ} \mathrm{C}$ for $4 \mathrm{~h}$ in air atmosphere and stored in vacuum desiccator.

General procedure for the preparation of symmetrical carboxylic anhydrides

To a stirred solution of carboxylic acid $(10 \mathrm{mmol})$ and PEG-1000 (5 mmol) was added $\mathrm{SO}_{4}{ }^{2-} / \mathrm{ZrO}_{2}(3 \mathrm{mmol})$ at room temperature and stirring was continued at $40{ }^{\circ} \mathrm{C}$ for the appropriate time. After completion of the reaction, as indicated by HPLC, the product was extracted with methylene chloride $(3 \times 5 \mathrm{~mL})$. The combined organic layer was dried over anhydrous $\mathrm{Na}_{2} \mathrm{SO}_{4}$ and then filtered over a pad of flash silica gel. Removal of the solvents in vacuo furnished the corresponding pure symmetrical carboxylic anhydrides. Fresh substrates were then recharged to the recovered catalyst system and then recycled under identical reaction

Bull. Chem. Soc. Ethiop. 2011, 25(2) 
conditions. The target substrates were characterized by elemental analysis, ${ }^{1} \mathrm{H}$ NMR or compared with their authentic samples. Spectroscopic data for selected products are given below.

4-Methylbenzoic anhydride (Table 2, entry 1). ${ }^{1} \mathrm{H}$ NMR $\left(400 \mathrm{MHz}, \mathrm{CDCl}_{3}\right) \delta(\mathrm{ppm}): 2.28(\mathrm{~s}$, $\left.\mathrm{CH}_{3}, 3 \mathrm{H}\right), 7.32(\mathrm{~m}, \mathrm{Ar}-\mathrm{H}, 2 \mathrm{H}), 7.86(\mathrm{~m}, \mathrm{Ar}-\mathrm{H}, 2 \mathrm{H})$. Anal. calcd for $\mathrm{C}_{16} \mathrm{H}_{14} \mathrm{O}_{3}$ : C, 75.54; H, 5.55; O, 18.89. Found: C, 75.57; H, 5.55; O, 18.88. IR (KBr, cm $\left.{ }^{-1}\right): 2917,2830,1782,1734,1641$, $1608,1514,1432,1383$.

4-Methoxybenzoic anhydride (Table 2, entry 2). ${ }^{1} \mathrm{H}$ NMR $\left(400 \mathrm{MHz}, \mathrm{CDCl}_{3}\right) \delta(\mathrm{ppm}): 3.72(\mathrm{~s}$, $\left.\mathrm{CH}_{3}, 3 \mathrm{H}\right), 7.27$ (m, Ar-H, 2H), 7.89 (m, Ar-H, 2H). Anal. calcd for $\mathrm{C}_{16} \mathrm{H}_{14} \mathrm{O}_{5}: \mathrm{C}, 67.11 ; \mathrm{H}, 4.92$; O, 27.95. Found: C, 67.13; H, 4.93; O, 27.94. IR (KBr, $\left.\mathrm{cm}^{-1}\right): 2949,2825,1785,1730,1637$, $1612,1522,1381,1258$.

4-Nitrobenzoic anhydride (Table 2, entry 4). ${ }^{1} \mathrm{H} \mathrm{NMR}\left(400 \mathrm{MHz}, \mathrm{CDCl}_{3}\right) \delta(\mathrm{ppm}): 8.19(\mathrm{~m}, \mathrm{Ar}-$ $\mathrm{H}, 2 \mathrm{H}), 8.37$ (m, Ar- $\mathrm{H}, 2 \mathrm{H})$. Anal. calcd for $\mathrm{C}_{14} \mathrm{H}_{8} \mathrm{~N}_{2} \mathrm{O}_{7}: \mathrm{C}, 53.12 ; \mathrm{H}, 2.55 ; \mathrm{N}, 8.87 ; \mathrm{O}, 35.44$. Found: C, 53.17; H, 2.55; N, 8.86; O, 35.42. IR (KBr, cm $\left.{ }^{-1}\right): 1789,1741,1634,1620,1517$, $1508,1353$.

Glutaric anhydride (Table 2, entry 10). ${ }^{1} \mathrm{H}$ NMR (400 MHz, $\left.\mathrm{CDCl}_{3}\right) \delta(\mathrm{ppm}): 1.97\left(\mathrm{~m}, \mathrm{CH}_{2}\right.$, $2 \mathrm{H}), 2.26\left(\mathrm{t}, 2 \times \mathrm{CH}_{2}, 4 \mathrm{H}\right)$. Anal. calcd for $\mathrm{C}_{5} \mathrm{H}_{6} \mathrm{O}_{3}: \mathrm{C}, 52.61 ; \mathrm{H}, 5.28 ; \mathrm{O}, 42.09$. Found: C, 52.63; H, 5.30; O, 42.07. IR (KBr, cm $\left.{ }^{-1}\right): 2967,2861,1781,1730,1635,1609,1519,1457$.

Succinic anhydride (Table 2, entry 11). ${ }^{1} \mathrm{H} \mathrm{NMR}\left(400 \mathrm{MHz}, \mathrm{CDCl}_{3}\right) \delta(\mathrm{ppm}): 2.94\left(\mathrm{~s}, \mathrm{CH}_{2}, 2 \mathrm{H}\right)$. Anal. calcd for $\mathrm{C}_{4} \mathrm{H}_{4} \mathrm{O}_{3}$ : C, 48.01; H, 4.03; O, 47.96. Found: C, 48.01; H, 4.03; O, 47.96. IR $\left(\mathrm{KBr}, \mathrm{cm}^{-1}\right): 2963,2867,1788,1732,1629,1611,1516,1462$.

2-Phenylacetic anhydride (Table 2, entry 17). ${ }^{1} \mathrm{H} \mathrm{NMR}\left(400 \mathrm{MHz}, \mathrm{CDCl}_{3}\right) \delta(\mathrm{ppm}): 3.64(\mathrm{~s}$, $\left.\mathrm{CH}_{2}, 2 \mathrm{H}\right), 7.27-7.38$ (m, Ar-H, 5H). Anal. calcd for $\mathrm{C}_{16} \mathrm{H}_{14} \mathrm{O}_{3}: \mathrm{C}, 75.55 ; \mathrm{H}, 5.53 ; \mathrm{O}, 18.87$. Found: C, 75.57; H, 5.55; O, 18.88. IR $\left(\mathrm{KBr}, \mathrm{cm}^{-1}\right)$ : 2957, 2863, 1786, 1739, 1630, 1614, 1519, 1467.

\section{RESULTS AND DISCUSSION}

The initial study was carried out using benzoic acid as the substrate to optimize the reaction conditions, and the results are summarized in Table 1. At first, eight type of phase transfer catalysts, PEG-200, PEG-400, PEG-600, PEG-800, PEG-1000, cetyltrimethylammonium bromide (CTAB), etradecyltrimethylammonium bromide (TTAB), and tetraethylammonium bromide (TEAB), were tested with $\mathrm{SO}_{4}{ }^{2-} / \mathrm{ZrO}_{2}$ as the catalyst precursor in the reaction (Table 1, entries 1-8), it was observed that PEG-1000 demonstrated the best performance, providing a $95 \%$ high yield (Table 1, entry 5). In addition, the catalyst $\mathrm{SO}_{4}{ }^{2-} / \mathrm{ZrO}_{2}$ and PEG-1000 are crucial for this reaction, and the lack of any component leads to no reaction or a lower yield. (Table 1 , entries 9 and 10). Therefore, the combination of $\mathrm{SO}_{4}{ }^{2-} / \mathrm{ZrO}_{2}$ and PEG-1000 was chosen as the optimal catalyst system for further exploration.

The influences of the amount of the catalyst $\mathrm{SO}_{4}{ }^{2-} / \mathrm{ZrO}_{2}$ on the reaction at $40{ }^{\circ} \mathrm{C}$ are shown in Figure 1. No reaction occurred in the absence of the catalyst, the increase of the catalyst amount (i.e. the ratio of $\left(\mathrm{SO}_{4}{ }^{2-} / \mathrm{ZrO}_{2}\right) /$ benzoic acid increased) enhanced the reaction and the yield reached maximum at 0.3 of the ratio. However, further addition of the catalyst resulted in the slow decrease of the yield. 
Figure 2 shows the influences of reaction temperature on the reaction. The catalytic activity increased with the increase in reaction temperature, and the yield reached maximum at $40{ }^{\circ} \mathrm{C}$. However, further increase in the temperature, decreased slowly the yield. These results show that the moderate temperature, such as $40{ }^{\circ} \mathrm{C}$ enhanced the reaction.

Table 1. Optimization of the reaction conditions for the synthesis of benzoic anhydride from benzoic acid ${ }^{\mathrm{a}}$.

\begin{tabular}{|c|c|c|c|l|}
\hline Entry & Phase transfer catalyst & Catalyst & Time (h) & Yield (\%) \\
\hline 1 & PEG-200 & $\mathrm{SO}_{4}{ }^{2-} / \mathrm{ZrO}_{2}$ & 2 & 85 \\
\hline 2 & PEG-400 & $\mathrm{SO}_{4}{ }^{2-} / \mathrm{ZrO}_{2}$ & 2 & 87 \\
\hline 3 & PEG-600 & $\mathrm{SO}_{4}{ }^{2-} / \mathrm{ZrO}_{2}$ & 1 & 91 \\
\hline 4 & PEG-800 & $\mathrm{SO}_{4}{ }^{2-} / \mathrm{ZrO}_{2}$ & 1 & 94 \\
\hline 5 & PEG-1000 & $\mathrm{SO}_{4}{ }^{2-} / \mathrm{ZrO}_{2}$ & 1 & 95 \\
\hline 6 & $\mathrm{CTAB}$ & $\mathrm{SO}_{4}{ }^{2-} / \mathrm{ZrO}_{2}$ & 1 & 93 \\
\hline 7 & $\mathrm{TTAB}$ & $\mathrm{SO}_{4}{ }^{2-} / \mathrm{ZrO}_{2}$ & 2 & 87 \\
\hline 8 & TEAB & $\mathrm{SO}_{4}{ }^{2-} / \mathrm{ZrO}_{2}$ & 2 & 84 \\
\hline 9 & - & $\mathrm{SO}_{4}{ }^{2-} / \mathrm{ZrO}_{2}$ & 6 & 81 \\
\hline 10 & PEG-1000 & - & 12 & 0 \\
\hline
\end{tabular}

${ }^{\mathrm{a}}$ Reaction conditions: benzoic acid $(10 \mathrm{mmol}), \mathrm{SO}_{4}{ }^{2-} / \mathrm{ZrO}_{2}(3 \mathrm{mmol}), \mathrm{PTC}(5 \mathrm{mmol}), 40{ }^{\circ} \mathrm{C}$. ${ }^{\mathrm{b}}$ Isolated yield

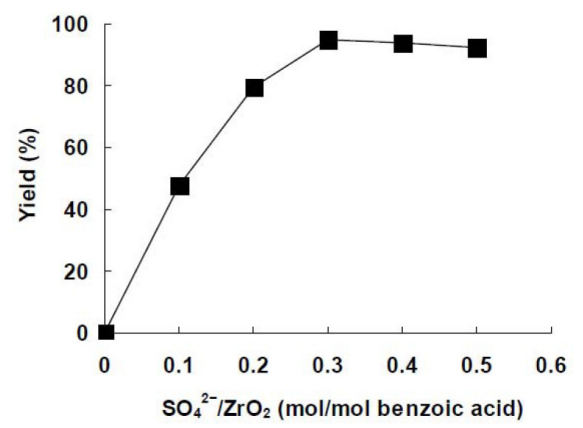

Figure 1. Influences of amount of $\mathrm{SO}_{4}{ }^{2-} / \mathrm{ZrO}_{2}$ on the reaction.

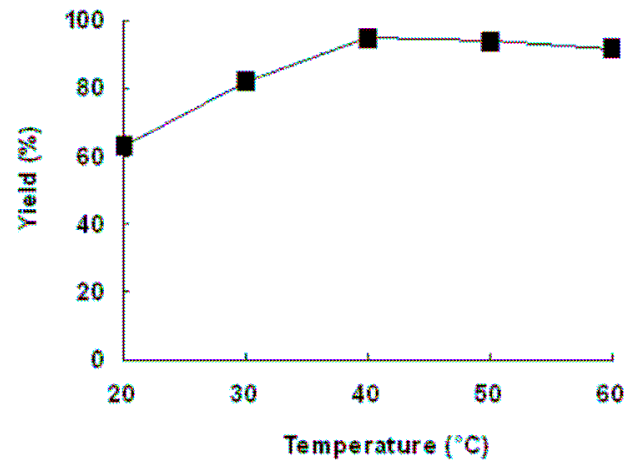

Figure 2. Influences of temperature on the reaction. 
In addition, the catalyst system could be typically recovered and reused for subsequent reactions (Figure 3). The recycling process involved the product layer (upper layer) was extracted with methylene chloride and the catalyst system layer (under layer) was concentrated to remove water produced in the reaction under vacuum. Fresh substrates were then recharged to the recovered catalytic system and the mixture was heated to react once again, and only $2.5 \%$ loss of weight was observed after 6 times recycling.

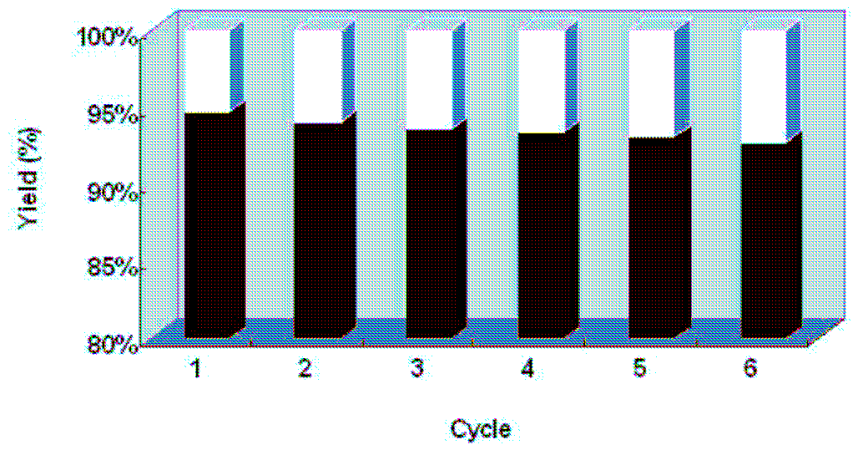

Figure 3. Repeating reactions using recovered catalyst system.

With these results in hand, the catalyst system was then applied to various carboxylic acids as summarized in Table 2. It is clear that various types of aromatic and alkyl acids, both monoacidic and dibasic, have been successfully converted to the corresponding carboxylic anhydrides in good to high yields (Table 2, entries 1-17), whereas the alkyl acids were less reactive, and the reactions proceeded more slowly, and longer reaction time was needed to reach good yields (Table 2, entries 9-17). Surprisingly, the conversion of dicarboxylic acids to the corresponding carboxylic anhydrides is faster and more efficient than that of monocarboxylic acids (Table 2, entries 8-11). In addition, the electron deficiency and nature of the substituents have influence on the conversion rate, carboxylic acids having electron-withdrawing groups (Table 2, entries 4-7 and 15-17) react more faster than those having electron-donating groups (Table 2, entries 1 and 2, 13 and 14).

Table 2. $\mathrm{SO}_{4}{ }^{2-} / \mathrm{ZrO}_{2} / \mathrm{PEG}-1000$-mediated conversion of carboxylic acids into carboxylic anhydrides ${ }^{\mathrm{a}}$.

\begin{tabular}{|l|l|l|l|l|}
\hline Entry & Substrate & Product & Time (h) & Yield (\%) \\
\hline b & &
\end{tabular}




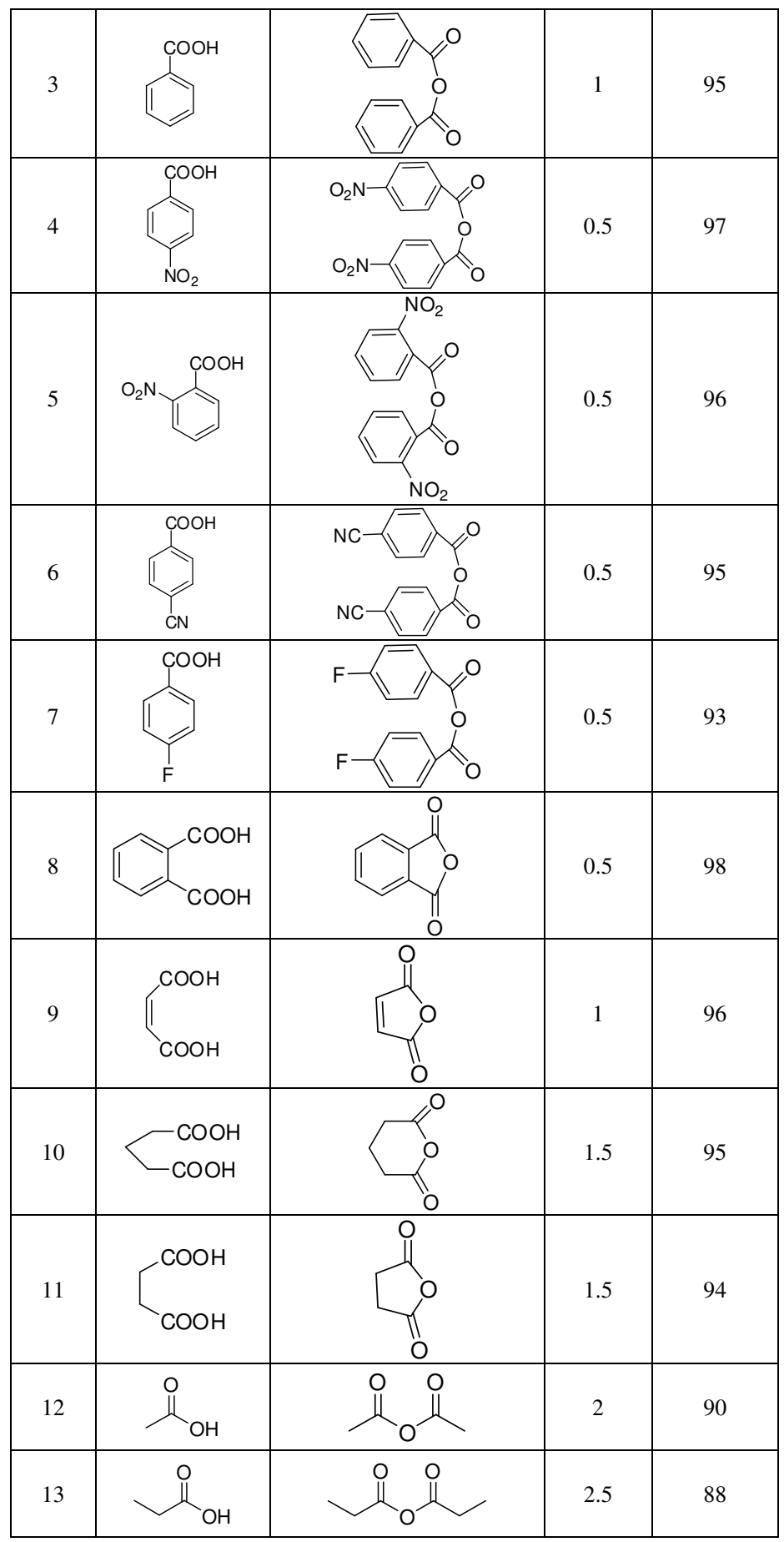

Bull. Chem. Soc. Ethiop. 2011, 25(2) 


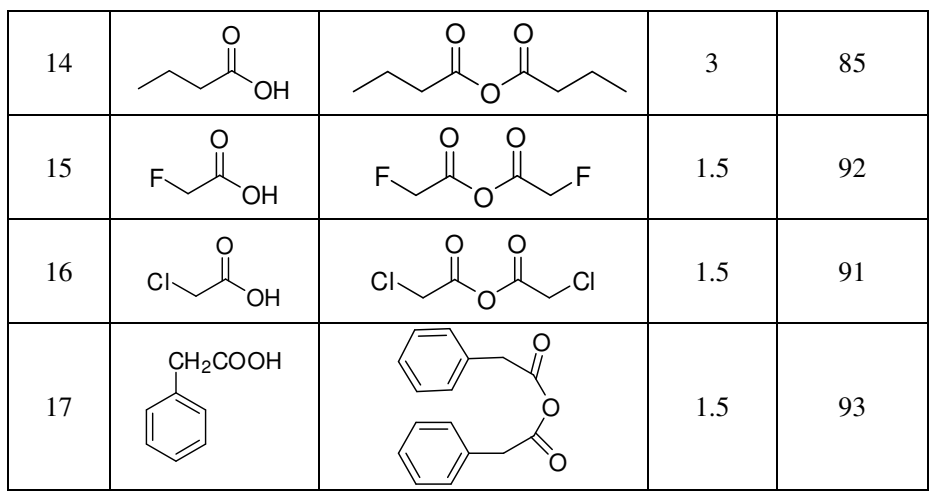

${ }^{a}$ Reaction conditions: carboxylic acid $(10 \mathrm{mmol}), \mathrm{SO}_{4}{ }^{2-} / \mathrm{ZrO}_{2}(3 \mathrm{mmol})$, PEG-1000 $(5 \mathrm{mmol}), 40{ }^{\circ} \mathrm{C} .{ }^{\mathrm{b}}$ Isolated yield.

\section{CONCLUSIONS}

In conclusion, we have disclosed an easy and straightforward high yielding preparation of various symmetrical carboxylic anhydrides by reaction of carboxylic acids with sulfated zirconia by PEG-1000 phase transfer catalysis. Most importantly, the catalysts are very easy to handle and can be recycled and reused without any significant loss of catalytic activity. The definition of the mechanism and the extension of this method to the synthesis of unsymmetrical carboxylic anhydrides are currently under investigation.

\section{ACKNOWLEDGEMENTS}

We thank the National Basic Research Program (973) of China (No. 613740101) and Natural Science Foundation of Jiangsu Province for support of this research.

\section{REFERENCES}

1. Held, H.; Rengstl, A.; Mayer, D. Acetic Anhydride and Mixed Fatty Acid Anhydrides: Ullmann's Encyclopedia of Industrial Chemistry, Wiley-VCH: Weinheim; 2002.

2. Tarbel, D.S. Acc. Chem. Res. 1969, 2, 296.

3. Ogliarous, M.A.; Wolfe, J.F. Synthesis of Carboxylic Acid, Esters and Their Derivatives, John Wiley: New York; 1991; p 198.

4. Rambacher, P.; Make, S. Angew. Chem. Int. Ed. 1968, 7, 465.

5. Sandler, S.R.; Karo, W. Organic Functional Group Preparation, Academi Press: New York; 1972.

6. Kazemi, F.; Kiasat, R. Phos. Sulf. Silicon 2003, 178, 2287.

7. Adduci, J.M.; Ramirez, R.S. Org. Prep. Proced. Int. 1970, 2, 321.

8. Kazemi, F.; Sharghi, H.; Nasseri, M. A. Synthesis 2004, 205.

9. Kawamura, Y.; Sato, Y.; Horie, T.; Tsukayama, M. Tetrahedron Lett. 1997, 38, 7893.

10. Kocz, R.; Roestamadji, J.; Mobashery, S. J. Org. Chem. 1994, 59, 2913.

11. Park, Y.D.; Kim, J.J.; Kim, H.K.; Cho, S.D.; Kang, Y.J.; Park, K.H.; Lee, S.G.; Yoon, Y.J. Synth. Commun. 2005, 35, 371;

12. Kim, J.J.; Park, Y.D.; Lee, W.S.; Cho, S.D.; Yoon, Y.J. Synthesis 2003, 1517. 
13. Kita, Y.; Akia, S.; Ajimura, N.; Yoahigi, M.; Tsugoshi, T.; Yasuda, H.; Tamura, Y. J. Org. Chem. 1986, 51, 4150.

14. Isobe, T.; Ishikawa, T. J. Org. Chem. 1999, 64, 6984.

15. Kaminki, Z.J.; Kolesinka, B.; Malgorzata, M. Synth. Commun. 2004, 34, 3349.

16. Chen, F.; Benoiton, N.L. Synthesis 1970, 710.

17. Kim, Y.H.; Kim, K.; Park, Y.J. Tetrahedron Lett. 1990, 31, 3893.

18. Keshavamurthy, K.S.; Vankar, Y.D.; Dhar, D.N. Synthesis 1982, 506.

19. Clarke, P.A.; Kayaleh, N.E.; Smith, M.A.; Baker, J.R.; Bird, S.J.; Chan, C. J. Org. Chem. 2002, 67, 5226.

20. Kim, J.; Jang, D.O. Synth. Commun. 2001, 31, 395.

21. Burton, S.G.; Kaye, P.T. Synth. Commun. 1989, 19, 3331.

22. Liang, Y.; Jwo, J.J. J. Mol. Catal. A: Chem. 2001, 170, 57.

23. Hajipour, A.R.; Mazloumi, G. Synth. Commun. 2002, 32, 23.

24. Fukuoka, S.; Takimoto, S.; Katsuki, T.; Yamaguchi, M. Tetrahedron Lett. 1987, 28, 4711.

25. Leadbeater, N.E.; Scott, K.A. J. Org. Chem. 2000, 65, 4770.

26. Srivastava, R.R.; Kabalba, G.W. Tetrahedron Lett. 1992, 33, 593.

27. Dhimitruka, I.; SantaLucia, J.J. Org. Lett. 2006, 8, 47.

28. Hu, Y.; Wang, J.X.; Li, S. Synth. Commun. 1997, 27, 243.

29. Martin, J.O. Acc. Chem. Res. 2004, 37, 506.

30. Maruoka, K. Org. Process Res. Dev. 2008, 12, 679.

31. Yang, H.M.; Huang, C.C. Ind. Eng. Chem. Res. 2007, 46, 7915.

32. Jones, A.R. Quaternary Ammonium Salts: Their Use in Phase Transfer Catalysis (Best Synthetic Methods), Elsevier: Amsterdam; 2001.

33. Hamilton, G.L.; Kanai, T.; Toste, F.D. J. Am. Chem. Soc. 2008, 130, 14984.

34. Hu, Y.L.; Wei, W.; Liu, Q.F.; Lu, M. Bull. Chem. Soc. Ethiop. 2010, $24,277$.

35. Arata, K. Appl. Catal. A: Gen. 1996, 146, 3.

36. Corma, A. Chem. Rev. 1995, 95, 559.

37. Li, X.; Nagaoka, K.; Simon, L.J.; Lercher, J.A. J. Catal. 2005, 230, 214. 